\title{
Asymmetry of frontal bristles and postocular setae in species and hybrids of the Anastrepha fraterculus complex (Diptera, Tephritidae)
}

\author{
João Maria G.A. Souza ${ }^{1,2}$, Milson Gouveia ${ }^{2}$, André L.P. Perondini ${ }^{1}$ and Denise Selivon ${ }^{1}$ \\ ${ }^{I}$ Departamento de Genética e Biologia Evolutiva, Instituto de Biociências, Universidade de São Paulo, \\ São Paulo, SP, Brazil. \\ ${ }^{2}$ Departamento de Biologia Celular e Genética, Universidade Federal do Rio Grande do Norte, Natal, \\ RN, Brazil.
}

\begin{abstract}
Asymmetry of the frontal bristles and postocular setae was studied in samples from natural populations and laboratory colonies of Anastrepha sp. 1 aff. fraterculus, of $A$. sp. 2 aff. fraterculus, and in F1 hybrids obtained from laboratory reciprocal crosses. Natural populations were sampled in a zone of sympatry and in two geographically distant regions with different climatic conditions. Asymmetry was scored as the differences between the number of bristles and of setae on the right and left sides of the head, males and females analyzed independently. The two traits exhibited variability according to the model of fluctuating asymmetry (FA). No significant differences among samples were found in the FA of frontal bristles. A significant FA was observed for the postocular setae of $A$. sp. 1 males from a southern population (Vacaria, RS) as compared to the asymmetry exhibited by males and females of some other samples. No significant differences in FA were observed among the interspecific hybrids and the laboratory samples of both parental species. The higher FA found in the males from Vacaria was attributed to climatic conditions prevailing in that region. The absence of a higher FA in hybrids may be related to the relatively recent evolutionary history of the two species.
\end{abstract}

Key words: developmental instability, fluctuating asymmetry, fruit flies, insect.

Received: September 28, 2005; Accepted: June 8, 2006.

\section{Introduction}

Fluctuating asymmetry (FA) is interpreted as the result of small disturbances during development, occurring at random on either side of a bilaterally symmetrical morphologic trait (van Valen, 1962, Palmer and Strobeck, 2003). Asymmetry is thought to reflect the developmental stability of an organism and, as such, thought to be under the influence of genetic and environmental stresses (Zakharov, 1992). Several biotic and abiotic stressors have been reported as being responsible for environmental influences on the symmetry of bilateral traits in different organisms (Leary and Allendorf, 1989, Parsons, 1990, Polak, 1993, Woods et al., 1999, Indrasamy et al., 2000), although other studies reported contradictory results (rev. Hoffman and Woods, 2003, Leamy and Klingenberg, 2005). One source of inconstancy may reside in the choice of traits to be used, since the FA response seems to be charac-

Send correspondence to Denise Selivon. Departamento de Genética e Biologia Evolutiva, Instituto de Biociências, Universidade de São Paulo, R. do Matão 277, 05508-900 São Paulo, SP, Brazil. E-mail: dselivon@ib.usp. br. ter-specific (Woods et al., 1999, Indrasamy et al., 2000, Hasson and Rössler, 2002). Analysis of relationships between genetic stresses and levels of FA has also yielded contradictory results. Meta-analyses and recent findings, for example, do not support either a general association of heterozygosity with FA (V申llestad et al., 1999, Leamy and Klingenberg, 2005) or an association of FA with fitness components (Lens et al., 2002a, Kruuk et al., 2003, Leamy and Klingenberg, 2005). However, in some instances, clear-cut differences in FA were found. In the tephritid fruit fly Bactrocera (Dacus) dorsalis, a significant increase in FA was observed during the period that preceded its eradication from Japan, as a result of the decrease in population size and loss of genetic diversity (Tsubaki, 1998). Another example is the bird Turdus helleri, in which variation in FA was correlated with the degree of habitat disturbance (Lens et al., 2002b). In zones of hybridization between two species, a decrease in developmental stability has been predicted, but conflicting results have been obtained (Markow and Ricker, 1991). In some hybridization zones, there was no excess of FA, while in others there was a positive correlation between FA and introgression (e.g., Jackson, 1973, 
Graham and Felley, 1985). The two contrasting results could be related to the relative age of the hybridization zones, as in more recent hybridizations there may not have been enough time for coadaptation of the two parental genomes (Graham and Felley, 1985).

Developmental stability is a crucial parameter that has to be assessed in programs of environmental monitoring and conservation (Leary and Allendorf, 1989), as well as in mass production of insects for use in the control of insect pests (Clarke and Mackenzie, 1992). Among the insect pests, the tephritid fruit flies represent one of the most important groups of worldwide distribution (White and Elson-Harris, 1992), and it has been suggested that FA may also be used as an additional indicator of the "quality" of individuals produced in biofabrics (Hunt et al., 1998).

Asymmetric patterns have been described for the head bristles in the fruit flies Ceratitis capitata (Hunt et al., 1998, Pires et al., 2004) and Anastrepha grandis (Pires et $a l ., 2004)$ and shown to be cases of FA. However, there are no studies on the degree of fluctuating asymmetry in fruit flies species submitted to different environmental conditions or genetic stresses. In this sense, it would be of interest to study asymmetry in species of fruit flies that present a wide geographic distribution and of which hybrids can be obtained in the laboratory. The A. fraterculus complex of cryptic species offers this opportunity. These species infest more than 67 host fruits of 17 different families (Zucchi, 2000) and are found from the southern United States through the Caribbean islands and down to central Argentina (White and Elson-Harris, 1992). Three species of the complex have been found in Brazil, and temporarily named A. sp. 1 aff. fraterculus, $A$. sp. 2 aff. fraterculus, and $A$. sp. 3 aff. fraterculus. They were found in zones of both allopatry and sympatry, where no hybrids were found as yet. However, hybrids can be obtained in the laboratory, but hybridization induces a reduction in egg hatching and in the survival of both males and females. Since the males are more affected, it causes a deviation in the adult sex ratio according to Haldane's rule (Selivon and Perondini, 1998, Selivon et al., 1999, 2004, 2005). Studies on reproductive isolation among samples of $A$. fraterculus from other regions of South America also showed reduced viability associated with Haldane's rule (Vera et al., 2006).

The present study was set to describe the levels of asymmetry of some characters in samples of $A$. sp. 1 aff. fraterculus and $A$. sp. 2 aff. fraterculus from populations either in sympatry or found in allopatry in areas with diverse climatic regimens, and to compare the asymmetry levels of these samples of natural populations with the asymmetry of flies from colonies maintained under controlled conditions in the laboratory. Another objective was to test whether or not hybridization of these two related species would change the level of asymmetry of some specific characters.

\section{Material and Methods}

\section{Anastrepha species}

The analysed species were $A$. sp. 1 aff. fraterculus and $A$. sp. 2 aff. fraterculus, herein shortly referred to as $A$. sp. 1 and $A$. sp. 2. They are closely related species of the Anastrepha fraterculus complex of cryptic species, hardly distinguishable from one another by usual taxonomic characteristics like the aculeus of the ovopositor. Clear distinction can however be achieved, based on conspicuous differences in the sex chromosomes, in four diagnostic loci of isozymes, in morphometric parameters of the wings and also the aculeus, and in eggshell morphology (Selivon and Perondini, 1998, Selivon et al., 2005). Two populations of each species were sampled in different regions. In a zone of sympatry, the valley of the Paraíba River (Selivon et al., 2005), A. sp. 1 was collected in guavas (Psidium guajava) and $A$. sp. 2 in oranges (Citrus spp), in the locality of Santa Isabel (State of São Paulo, $23^{\circ} 18^{\prime} \mathrm{S}, 46^{\circ} 13^{\prime} \mathrm{W}$, altitude $554 \mathrm{~m}$ ). The other $A$. sp. 1 sample was obtained from guavas collected in Vacaria (State of Rio Grande do Sul, $28^{\circ} 30^{\prime} \mathrm{S}, 50^{\circ} 54^{\prime} \mathrm{W}$, altitude $950 \mathrm{~m}$ ), and the other $A$. sp. 2 in Natal (State of Rio Grande do Norte, $05^{\circ} 48^{\prime}$ S, 35 $5^{\circ} 13^{\prime}$ W, sea level). The $A$. sp. 1 samples were coded as SIg (ㅁta. Isabel, guavas) and Vac (Vacaria), and the $A$. sp. 2 samples as SIo (ㅁta. Isabel, oranges) and Nat (Natal). The infested fruits were brought to the laboratory, and samples of the emerged adults were separated by sex and preserved in $70 \%$ ethanol. Other adults that emerged from the Sta. Isabel samples were used in the interspecific crossing experiments.

Additionally, an $A$. sp. 1 (Lab1) and an A.sp. 2 (Lab2) sample were taken from laboratory colonies that have been maintained in the laboratory for 29 generations, and preserved in $70 \%$ ethanol. These colonies derived from flies collected in Santa Isabel, in guavas and oranges, respectively.

\section{Crosses}

Virgin adults of $A$. sp. 1 and $A$. sp. 2 emerged in the laboratory were used for the interspecific reciprocal crosses. The hybrid offspring of these crosses were coded as H12 (sp. 1 females X sp. 2 males) and H21 (sp. 2 females $\mathrm{X}$ sp. 1 males), respectively. The interspecific crosses were made according to Selivon et al. (1999, 2005). Briefly, five mating pairs were maintained in small population cages and fed corn meal protein hydrolysate, sugar and water. Guavas were furnished as substrate for larval development. The cages were maintained in a room with controlled temperature $\left(\sim 25^{\circ} \mathrm{C}\right)$, humidity $(\sim 70 \%)$, and a natural photoperiod regimen. Emerged F1 adult flies were collected and preserved in $70 \%$ ethanol. 


\section{Analyzed structures}

Figure 1 shows the location of the two bilateral structures examined on the head of the flies, the frontal bristles and the postocular setae (Norrbom et al., 1999). The frontal bristles are arranged in two rows, one on each side of the frons, parallel to the eyes, while the postocular setae are arranged in one row at the posterior rim of each eye, from the top toward the ventral side of the head. The specimens presented in Figure 1 were prepared for scanning electron microscopy according to Selivon and Perondini (1998), and examined under a Zeiss DMS 940 electron microscope.

\section{Asymmetry measurements}

The adult heads were examined under a stereomicroscope, and the number of specific bristles and setae on each side of male and female heads were scored separately. Sample size is given under Results for clarity. Asymmetry scores were calculated as the differences between the number of bristles and setae on right and left side (R-L), and asymmetry expressed by the modules, $|\mathrm{R}-\mathrm{L}|$, of the scores for each trait (Palmer and Strobeck, 2003). The samples were scored twice at different times by one of the authors (JMGAS), the two scores confronted, and discrepancies corrected by reexamining the involved specimens.

\section{Statistical analysis}

It is often observed that the degree of asymmetry is positively correlated to the magnitude of the trait measured. This scaling problem is usually corrected by dividing the asymmetry score of each individual ( $\mathrm{R}$ - L) by the average magnitude of the trait measure for that individual on each
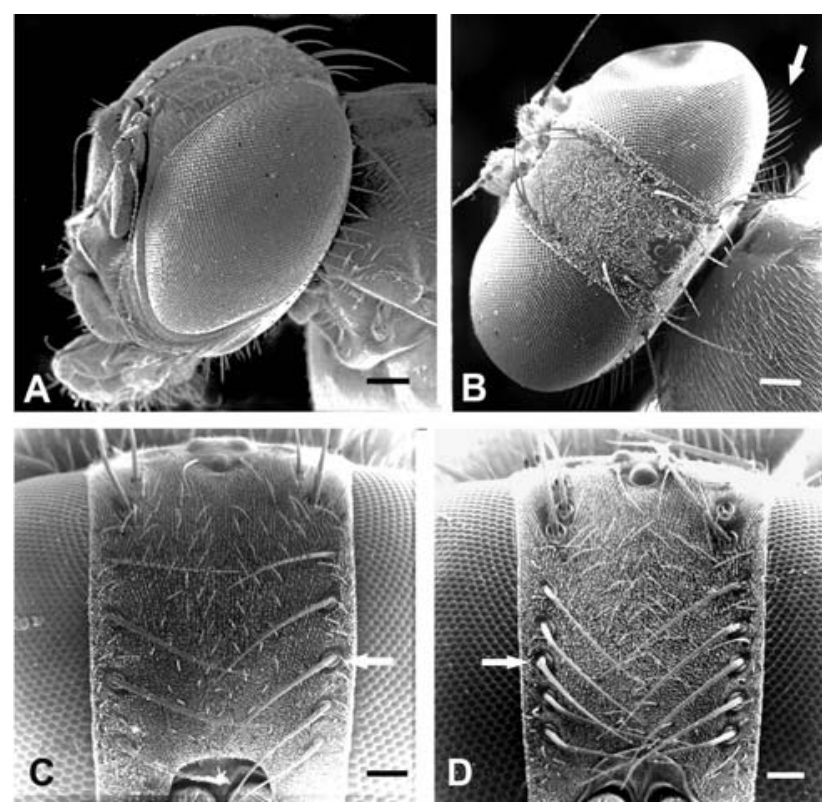

Figure 1 - Scanning electron micrographs of $A$. sp. 1 heads: (A) frontolateral view of the head; (B) dorsal view showing the postocular setae (arrow); frontal bristles (arrows) of an asymmetric (C) and a symmetric (D) individual. Scales in (A) and $(B)=200 \mu \mathrm{m} ;(C)$ and $(D)=100 \mu \mathrm{m}$. side of the body $(\mathrm{R}+\mathrm{L} / 2)$ (Palmer and Strobeck, 2003). In order to detect possible scaling problems, correlations between the asymmetry value for each trait and the average number of bristles and setae on each side of the head were calculated (Palmer and Strobeck, 2003). Two tests were employed to evaluate the type of asymmetry, fluctuating asymmetry (FA, defined as random variation on each side of the bilateral traits), directional asymmetry (DA, greater trait development on a certain side of the body), or antisymmetry (AS, deviation from symmetry, forming a platykurtic or bimodal distribution) (van Valen, 1962), presented by the traits. First, the number of bristles and setae on each side of the head was compared by a paired $t$-test that indicates if a distribution has or not a mean value equal to zero. Secondly, the means, skewness and kurtosis of the signed asymmetry distributions were calculated, since - for traits exhibiting FA - the values should be normally distributed around zero (van Valen, 1962, Palmer and Strobeck, 2003). The differences in the level of unsigned asymmetry for each trait among the different samples were evaluated by two-factor ANOVA (sex and sample) and Newman-Keuls tests, preceded by the Bartlet test for homogeneity of variances (Zar, 1999). An overall, holistic asymmetry for each sample was calculated by adding the asymmetry of the two traits for each individual, after having standardized the signed asymmetry values for each trait to a mean equal to zero and a variance equal to one (Indrasamy et al., 2000). The pooled asymmetry was tested by ANOVA, as mentioned above. The statistical tests were performed with the Statistica 6.0 (Statsoft Inc., 1997) software.

\section{Results}

Asymmetry for each trait was scored independently for male and female individuals, and the mean values are shown in Table 1. Regression of the individual asymmetry scores for the average number of frontal bristles and postocular setae on each side of each individual showed no significant correlations in the samples (data not shown). Hence, as indicated by Palmer and Strobeck (2003), no correction for scaling was necessary for the asymmetry scores of bristles and setae in the analyzed samples.

The results of the paired $t$-test applied to values of the right and left side of individuals from the different samples showed that the distributions of the asymmetry scores obtained for the two bilateral structures had mean values equal to zero (data not shown). Only in two cases, the frontal bristles of Nat and H21 females, the distributions presented a slight departure from the mean zero. These distributions, however, showed opposite results, a skewing to the left in the Nat sample and to the right in H21, suggesting that they do not really represent cases of DA. Indeed, the signed asymmetry variation for both traits in all samples must represent cases of true FA, since no skewness nor kurtosis were found for the distributions of $\mathrm{R}$ - L values, as shown in Table 1. 
Table 1 - Means, skewness and kurtosis of signed asymmetry distributions and unsigned asymmetry of frontal setae and postocular bristles in samples of A. sp.1 (Vac, SIg, Lab1), A. sp.2 (Nat, SIo, Lab2) and hybrids (H21, H12) from reciprocal laboratory crosses.

\begin{tabular}{|c|c|c|c|c|c|c|c|c|c|}
\hline \multirow{2}{*}{$\begin{array}{l}\text { Setae/ } \\
\text { bristles }\end{array}$} & \multirow[b]{2}{*}{ Gender } & \multirow[b]{2}{*}{ Samples } & \multirow[b]{2}{*}{$\mathrm{N}$} & \multicolumn{4}{|c|}{ Asymmetry (R-L) } & \multicolumn{2}{|c|}{ Unsigned asymmetry } \\
\hline & & & & Mean & s.d. & Skewness & Kurtosis & Mean & s.d. \\
\hline \multirow[t]{16}{*}{ Frontal } & Males & Nat & 100 & -0.06 & 0.763 & $0.086 \mathrm{~ns}$ & $0.895 \mathrm{~ns}$ & 0.46 & 0.610 \\
\hline & & SIo & 99 & 0.08 & 0.817 & $-0.151 \mathrm{~ns}$ & $0.272 \mathrm{~ns}$ & 0.55 & 0.611 \\
\hline & & Vac & 79 & -0.03 & 0.891 & $-0.396 \mathrm{~ns}$ & $-0.230 \mathrm{~ns}$ & 0.71 & 0.535 \\
\hline & & SIg & 100 & -0.08 & 0.8 & $0.146 \mathrm{~ns}$ & $-0.161 \mathrm{~ns}$ & 0.56 & 0.574 \\
\hline & & Lab1 & 50 & -0.02 & 0.769 & $0.315 \mathrm{~ns}$ & $-0.457 \mathrm{~ns}$ & 0.54 & 0.542 \\
\hline & & Lab2 & 50 & -0.14 & 1.049 & $-0.039 \mathrm{~ns}$ & $-0.243 \mathrm{~ns}$ & 0.74 & 0.751 \\
\hline & & $\mathrm{H} 21$ & 99 & -0.01 & 0.776 & $-0.273 \mathrm{~ns}$ & $0.893 \mathrm{~ns}$ & 0.48 & 0.612 \\
\hline & & $\mathrm{H} 12$ & 66 & 0.11 & 0.636 & $0.281 \mathrm{~ns}$ & $0.504 \mathrm{~ns}$ & 0.38 & 0.519 \\
\hline & Females & Nat & 103 & -0.18 & 0.772 & $0.183 \mathrm{~ns}$ & $-0.325 \mathrm{~ns}$ & 0.56 & 0.554 \\
\hline & & SIo & 103 & 0.00 & 0.779 & $-0.126 \mathrm{~ns}$ & $-0.332 \mathrm{~ns}$ & 0.54 & 0.556 \\
\hline & & Vac & 100 & 0.06 & 0.763 & $-0.380 \mathrm{~ns}$ & $-0.412 \mathrm{~ns}$ & 0.54 & 0.540 \\
\hline & & SIg & 96 & -0.03 & 0.76 & $-0.241 \mathrm{~ns}$ & $0.308 \mathrm{~ns}$ & 0.49 & 0.580 \\
\hline & & Lab1 & 50 & -0.04 & 0.781 & $-0.463 \mathrm{~ns}$ & $0.027 \mathrm{~ns}$ & 0.52 & 0.579 \\
\hline & & Lab2 & 50 & -0.16 & 0.817 & $0.308 \mathrm{~ns}$ & $-0.192 \mathrm{~ns}$ & 0.60 & 0.571 \\
\hline & & $\mathrm{H} 21$ & 75 & 0.16 & 0.678 & $-0.207 \mathrm{~ns}$ & $0.861 \mathrm{~ns}$ & 0.43 & 0.550 \\
\hline & & $\mathrm{H} 12$ & 100 & 0.11 & 0.777 & $0.201 \mathrm{~ns}$ & $-0.485 \mathrm{~ns}$ & 0.55 & 0.557 \\
\hline \multirow[t]{16}{*}{ Postocular } & Males & Nat & 100 & -0.15 & 1.919 & $-0.394 \mathrm{~ns}$ & $0.028 \mathrm{~ns}$ & 1.51 & 1.185 \\
\hline & & SIo & 99 & -0.26 & 1.601 & $0.426 \mathrm{~ns}$ & $0.403 \mathrm{~ns}$ & 1.27 & 0.998 \\
\hline & & Vac & 79 & -001 & 2.091 & $-0.104 \mathrm{~ns}$ & $0.029 \mathrm{~ns}$ & 1.68 & 1.225 \\
\hline & & SIg & 100 & 0.01 & 1.418 & $-0.191 \mathrm{~ns}$ & $-0.200 \mathrm{~ns}$ & 1.05 & 0.947 \\
\hline & & Lab1 & 50 & 0.22 & 1.787 & $-0.011 \mathrm{~ns}$ & $0.403 \mathrm{~ns}$ & 1.34 & 1.188 \\
\hline & & Lab2 & 50 & -0.14 & 1.927 & $0.417 \mathrm{~ns}$ & $-0.185 \mathrm{~ns}$ & 1.52 & 0.931 \\
\hline & & $\mathrm{H} 21$ & 99 & 0.17 & 1.803 & $-0.244 \mathrm{~ns}$ & $0.604 \mathrm{~ns}$ & 1.42 & 1.204 \\
\hline & & $\mathrm{H} 12$ & 66 & -0.14 & 1.796 & $-0.216 \mathrm{~ns}$ & $-0.654 \mathrm{~ns}$ & 1.44 & 1.069 \\
\hline & Females & Nat & 103 & 0.04 & 1.633 & $-0.160 \mathrm{~ns}$ & $0.113 \mathrm{~ns}$ & 1.24 & 1.052 \\
\hline & & SIo & 103 & -0.23 & 1.682 & $-0.027 \mathrm{~ns}$ & $-0.349 \mathrm{~ns}$ & 1.32 & 1.059 \\
\hline & & Vac & 100 & 0.12 & 1.559 & $0.091 \mathrm{~ns}$ & $-0.059 \mathrm{~ns}$ & 1.14 & 1.064 \\
\hline & & SIg & 96 & 0.16 & 1.475 & $-0.175 \mathrm{~ns}$ & $-0.236 \mathrm{~ns}$ & 1.18 & 0.894 \\
\hline & & Lab1 & 50 & 0.06 & 1.531 & $-0.463 \mathrm{~ns}$ & $0.027 \mathrm{~ns}$ & 1.14 & 1.010 \\
\hline & & Lab2 & 50 & -0.22 & 1.753 & $0.308 \mathrm{~ns}$ & $-0.192 \mathrm{~ns}$ & 1.34 & 1.359 \\
\hline & & $\mathrm{H} 21$ & 75 & 0.16 & 1.669 & $0.152 \mathrm{~ns}$ & $-1.062 \mathrm{~ns}$ & 1.39 & 0.928 \\
\hline & & H12 & 100 & -0.04 & 1.803 & $-0.055 \mathrm{~ns}$ & $-0.715 \mathrm{~ns}$ & 1.42 & 1.027 \\
\hline
\end{tabular}

The mean values of the unsigned asymmetry scores, $|\mathrm{R}-\mathrm{L}|$, of each trait for males and females from different samples are shown in Table 1. Differences in asymmetry values were compared individually for each trait. The ANOVA test showed distinct patterns of variation for the two traits scored (Table 2). For the frontal bristles, no significant differences in FA were found either between the sexes, or the samples, within or between the species $A$. sp. 1 and $A$. sp. 2, or between their reciprocal hybrids. Similar results were found when the FA of postocular setae was compared between samples from laboratory colonies and the reciprocal hybrids (Table 2). However, significant interactions between sex and sample in the FA levels of postocular setae were found among the samples of natural populations, and in the comparisons of hybrids either to laboratory samples or to samples from natural populations (Table 2). The Newman-Keuls test showed the following results: (1) among the samples of natural populations of the two species, $A$. sp. 1 males from Vac showed a higher FA than females of the same population ( $\mathrm{p}=0.011)$, than conspecific SIg males $(\mathrm{p}=0.002)$ and females $(\mathrm{p}=0.019)$, and than $A$. sp. 2 males from SIo ( $p=0.048)$; (2) among the natural populations and laboratory samples, FA was higher in the males from $\mathrm{Vac}$ than in their conspecific females $(p=0.027)$, and than in both males $(p=0.004)$ and females $(p=0.043)$ from SIg; (3) comparisons among samples of 
Table 2 - Two-factor ANOVA (sex and sample) for the unsigned fluctuating asymmetry values of frontal bristles and postocular setae in samples from natural and laboratory populations of $A$. sp. 1 and $A$. sp. 2 and their hybrids.

\begin{tabular}{|c|c|c|c|c|c|c|c|c|c|c|c|c|}
\hline \multirow[b]{2}{*}{ Source } & \multicolumn{6}{|c|}{ Frontal } & \multicolumn{6}{|c|}{ Postocular } \\
\hline & df effect & MS effect & df error & MS error & $\mathrm{F}$ & p-level & df effect & MS effect & df error & MS error & $\mathrm{F}$ & p-level \\
\hline & & \multicolumn{5}{|c|}{ Natural populations } & \multicolumn{6}{|c|}{ Natural populations } \\
\hline Sex & 1 & 0.230 & 3 & 0.623 & 0.370 & 0.586 & 1 & 4.899 & 3 & 4.422 & 1.108 & 0.370 \\
\hline Samples & 3 & 0.469 & 3 & 0.623 & 0.753 & 0.590 & 3 & 3.399 & 3 & 4.422 & 0.769 & 0.583 \\
\hline \multirow[t]{2}{*}{ Sex*samples } & 3 & 0.623 & 772 & 0.326 & 1.909 & 0.127 & 3 & 4.422 & 772 & 1.111 & 3.979 & $0.008 *$ \\
\hline & & \multicolumn{5}{|c|}{ Natural and laboratory populations } & \multicolumn{6}{|c|}{ Natural and laboratory populations } \\
\hline Sex & 1 & 0.546 & 5 & 0.421 & 1.297 & 0.306 & 1 & 6.361 & 5 & 2.714 & 2.344 & 0.186 \\
\hline Samples & 5 & 0.566 & 5 & 0.421 & 1.344 & 0.377 & 5 & 2.422 & 5 & 2.714 & 0.892 & 0.548 \\
\hline \multirow[t]{2}{*}{ Sex*samples } & 5 & 0.421 & 968 & 0.337 & 1.247 & 0.285 & 5 & 2.714 & 968 & 1.118 & 2.426 & $0.034 *$ \\
\hline & & \multicolumn{5}{|c|}{ Laboratory populations and hybrids } & \multicolumn{6}{|c|}{ Laboratory populations and hybrids } \\
\hline Samples & 3 & 1.177 & 3 & 0.587 & 2.006 & 0.291 & 3 & 0.898 & 3 & 0.273 & 3.283 & 0.178 \\
\hline \multirow[t]{2}{*}{ Sex*samples } & 3 & 0.587 & 532 & 0.342 & 1.716 & 0.163 & 3 & 0.273 & 532 & 1.146 & 0.239 & 0.869 \\
\hline & & \multicolumn{5}{|c|}{ Natural populations and hybrids } & \multicolumn{6}{|c|}{ Natural populations and hybrids } \\
\hline Sex & 1 & 0.230 & 3 & 0.608 & 0.379 & 0.582 & 1 & 3.671 & 5 & 2.867 & 1.281 & 0.309 \\
\hline Samples & 3 & 0.479 & 3 & 0.608 & 0.788 & 0.575 & 5 & 2.691 & 5 & 2.867 & 0.939 & 0.527 \\
\hline Sex*samples & 3 & 0.608 & 772 & 0.327 & 1.861 & 0.135 & 5 & 2.867 & 1108 & 1.121 & 2.557 & $0.026 *$ \\
\hline
\end{tabular}

(*) significant at 0.05 .

natural populations and the laboratory hybrids showed similar results, Vac males exhibiting a higher FA than their conspecific females $(p=0.027)$, and than males $(p=0.004)$ and females $(\mathrm{p}=0.05)$ from SIg, although the difference with the latter one was at the limit of significance.

Comparisons of the pooled standardized FA values of the two traits among samples by 2-way ANOVA showed no significant differences in FA levels (data not shown), even for the cases of Vac males which had shown higher FA levels of the postocular setae than some of the samples, as described above.

\section{Discussion}

The results of the analysis reported here showed, as previously observed for the frontal bristles of Anastrepha grandis and Ceratitis capitata (Pires et al., 2004), that frontal bristles and postocular setae of $A$. sp. 1 and $A$. sp. 2 consistently exhibit a FA pattern of variation. They also indicate that the two traits may show different levels of disturbance. The frontal bristles, for example, showed the same level of FA in the two species, $A$. sp. 1 and $A$. sp. 2, regardless of sex and whether the flies derived from a natural population, laboratory colonies or were hybrids obtained in the laboratory. The same was found for the postocular setae of $A$. sp. 2 and some samples of $A$. sp. 1 (SIg population). However, $A$. sp. 1 males from the Vac population exhibited a significantly higher FA of the postocular setae when compared to conspecific individuals. These findings are in line to other studies indicating that an asymmetry response seems to be related to noises in the development of specific characters, rather than to an overall developmental instability of the individuals (Woods et al., 1999, Indrasamy et al., 2000, Hasson and Rössler, 2002, Leamy and Klingenberg, 2005 ). Indeed, the pooled asymmetry of the two traits indicated no significant differences among the samples, a result that masks the significant FA of postocular setae in the Vac males.

Variation at the genotypic level as related to FA levels is controversial, and has not been confirmed in metaanalysis and recent studies (Vøllestad et al., 1999, Lens et al., 2002a, Kruuk et al., 2003, Leamy and Klingenberg, 2005). In line with these arguments, analysis of 19 enzymatic loci indicated that the heterozygosity of the Vac population does not differ significantly from those observed for other populations of the same species (A. sp. 1), and is similar to that of $A$. sp. 2 (Selivon et al., 2005). Hence, the higher FA of Vac males cannot be attributed to a lower level of heterozygosity.

The higher FA of Vac males may be related to environmental stress. Stressful conditions have been associated to increased FA in some studies, for example, in the bird Turdus helleri (Lens et al., 2002b) and in the fruit flies Bactrocera (Dacus) dorsalis (Tsubaki, 1998) and Drosophila melanogaster (Woods et al., 1999). Temperature is an abiotic factor that has been shown to be related to phenotypic variation. In Drosophila melanogaster, an increase in the length variation of the body (David et al., 1983) and wings (Tantawy and Mallah, 1961) was observed at the extremes of the experimental temperatures 
employed. In D. melanogaster and D. buzatti, an increase in the FA of sternopleural bristles, number of branches in the arista, and in the wing length was also found at the extremes of the experimental temperature range (Imasheva et al., 1997). In the aphid Myzus persicae, a temperature-related phenotypic plasticity was observed, but there was no linear relationship between the temperature values and the degree of FA (Kanegae and Lomônaco, 2003). Of all the localities where samples were taken for the present analysis, harsher conditions certainly prevail in Vacaria, due to its southern latitude and higher altitude. Thus, one may consider that the higher FA of $A$. sp. 1 males from Vacaria may be related to the more severe climatic conditions of that region. A similar effect, however, was not observed in the SIo and Nat samples of $A$. sp. 2, taken from localities at expressive latitudinal distance. It is therefore reasonable to consider that the specific climatic conditions of the two regions may not differ enough so as to interfere with the developmental processes of these flies, or that $A$. sp. 2 shows a different response to stress, exhibiting a distinctive level of buffering in its development.

It is relevant to note that no differences in asymmetry were observed in $\mathrm{F} 1$ hybrids between $A$. sp. 1 and $A$. sp. 2 . These results are in line to the data on other species, in which hybridization did not increase the phenotypic variation in the F1 generation either (Jackson, 1973). On the other hand, there are hybridized populations that show higher levels of developmental instability (Leary et al., 1985, Graham and Felley, 1985). In a study on hybridization between $D$. melanogaster and D. simulans, a significant increase in the FA of sternopleural and fronto-orbital bristles and of wing length was found in F1 females, but not in males (Markow and Ricker, 1991). The contrasting asymmetry response to hybridization was interpreted as related to the degree of isolation and genomic incompatibility between the two species (Graham and Felley, 1985). Since it is estimated that the species of the fraterculus complex have a recent evolutionary origin (Morgante et al., 1980, Smith-Caldas et al., 2001, Selivon et al., 2004, 2005), it could be assumed that genomic coadaptation is still at such a level that hybridization was not sufficient to induce alterations in the developmental stability of the first generation of hybrids.

However, an alternative hypothesis to explain the fact that FA was not increased in the F1 hybrids is based on the observation that hybridization between the two species of Anastrepha causes a decrease in viability of both sexes and an alteration in the F1 progenies according to Haldane's rule (Selivon et al., 1999, 2005). Differential mortality among the offspring may be masking the level of asymmetry, since the nonviable individuals might have exhibited high levels of FA, if they had survived. Thus, following hybridization, the survivors would exhibit levels of FA similar to those of their parents (Campbell et al., 1998).
Bristle asymmetry may also be implicated in reducing the mating success of males of some dipteran species. It was observed that Drosophila pseudoobscura males which had mated exhibited less asymmetry than males which did not copulate (Markow and Ricker, 1992). Similarly, asymmetric scorpion fly (Panorpa japonica) males showed less mating success than the symmetric ones (Tornhill, 1992). In the tephritid $C$. capitata, symmetric males also had greater mating success than the asymmetric ones (Hunt et al., 1998), observations that have been confirmed in natural populations (Hunt et al., 2004).

Additional analyses are still required to ascertain whether or not the asymmetric variation of the frontal or other head bristles has any implication in the mating success in Anastrepha species, and to evaluate the robustness of these traits as indicators of stressful conditions.

\section{Acknowledgments}

This work was supported by FAPESP (03/02698-3). The authors thank Paulo A. Otto and two anonymous referees for their suggestions. JMGAS had a PICD/CAPES doctoral scholarship; DS is fellow of CNPq.

\section{References}

Campbell WB, Emlen JM and Hershberger WK (1998) Thermally induced chronic developmental stress in coho salmon: Integrating measures of mortality, early growth, and developmental instability. Oikos 81:398-410.

Clarke GM and Mackenzie JA (1992) Fluctuating asymmetry as a quality control indicator for insect mass rearing projects. J Econ Entomol 85:2045-2050.

David JR, Allemand R, Van Herreweg J and Cohet Y (1983) Ecophysiology: Biotic factors. In: Ashburner M, Carson HL and Thompson JL (eds) The Genetics and Biology of Drosophila. Academic Press, London, pp 105-170.

Graham JH and Felley JD (1985) Genomic coadaptation and developmental stability within introgressed populations of Enneacanthus gloriosus and E. obesus (Pisces, Centrarchidae). Evolution 39:104-114.

Hasson O and Rössler Y (2002) Character-specific homeostasis dominates fluctuating asymmetry in the medfly (Diptera, Tephritidae). Florida Entomol 85:73-82.

Hoffman AA and Woods RE (2003) Associating environmental stress with developmental stability: Problems and patterns. In: Polak M (ed.) Developmental Instability. Causes and Consequences. Oxford Univ. Press, New York, pp 387-401.

Hunt MK, Crean SC, Wood RJ and Gilburn AS (1998) Fluctuating asymmetry and sexual selection in the Mediterranean fruitfly (Diptera, Tephritidae). Biol J Linnean Soc 64:385388.

Hunt MK, Nicholls CJ, Wood RJ, Predon AP and Gilburn AS (2004) Sexual selection for symmetrical male medflies (Diptera, Tephritidae) confirmed in the field. Biol J Linnean Soc 81:347-355.

Imasheva AG, Loeschcke V, Zhivotovsky LA and Lazebny OE (1997) Effects of extreme temperatures on phenotypic variation and developmental stability in Drosophila 
melanogaster and D. buzzatti. Biol J Linnean Soc 61:117126.

Indrasamy H, Woods RE, McKenzie JA and Batterham P (2000) Fluctuating asymmetry for bristle characters in Notch mutants of Drosophila melanogaster. Genetics 109:151-159.

Jackson JF (1973) The phenetics and ecology of a narrow hybrid zone. Evolution 27:58-68.

Kanegae AP and Lomônaco C (2003) Plasticidade morfológica, reprodutiva e assimetria flutuante de Myzuz persicae (Sulzter) (Hemiptera, Aphidae) sob diferentes temperaturas. Neotrop Entomol 32:37-43.

Kruuk LEB, Slate J, Pemberton JM and Clutton-Brock TH (2003) Fluctuating asymmetry in a secondary trait: No associations with individual fitness, environmental stress or inbreeding, and no heritability. J Evo Biol 16:101-113.

Leamy LJ and Klingenberg CP (2005) The genetics and evolution of fluctuating asymmetry. Ann Rev Ecol Evol Syst 36:1-21.

Leary FR, Allendorf FW and Knudson RL (1985) Developmental instability and high meristic counts in interspecific hybrids of salmonid fishes. Evolution 39:1318-1326

Leary FR and Allendorf FW (1989) Fluctuating asymmetry as an indicator of stress: Implications for conservation biology. Trends Ecol Evol 4:214-217.

Lens L, Van Dongen S, Kark S and Matthysen E (2002a) Fluctuating asymmetry as an indicator of fitness: Can we bridge the gap between studies? Biol Rev 77:27-38.

Lens L, Van Dongen S and Matthysen E (2002b) Fluctuating asymmetry as an early warning system in the critically endangered Taita thrush. Conservation Biol 16:479-487.

Markow TA and Ricker JP (1991) Developmental stability in hybrids between the siblings species pair, Drosophila melanogaster and Drosophila simulans. Genetica 84:115121.

Markow TA and Ricker JP (1992) Male size, developmental stability, mating success in natural populations of three Drosophila species. Heredity 69:122-127.

Morgante JS, Malavasi A and Bush GL (1980) Biochemical systematics and evolutionary relationships of neotropical Anastrepha. Ann Entomol Soc Amer 73:622-630.

Norrbom AL, Zucchi RA and Hernández-Ortiz V (1999) Phylogeny of the genera Anastrepha and Toxotrypana (Trypetinae, Toxotrypanini) based on morphology. In: Aluja M and Norrbom AL (eds.) Fruit Flies (Tephritidae): Phylogeny and Evolution of Behavior. CRC Press, Boca Raton, pp 299-342.

Palmer AR and Strobeck C (2003) Fluctuating asymmetry revisited. In: Polak M (ed) Developmental Instability (DI): Causes and Consequences. Oxford Univ Press, NY, pp 279319.

Parsons PA (1990) Fluctuating asymmetry: An epigenetic measure of stress. Biol Rev 65:131-145.

Pires AO, Selivon D and Perondini ALP (2004) Variation in symmetrical patterns of development in Anastrepha grandis and Ceratitis capitata. In: Barnes B (ed) Proc. 6th International Fruit Flies Symposium, Isteg Scientific Publ., Irene, pp 259-263.

Polak M (1993) Parasites increase fluctuating asymmetry of male Drosophila nigrospiracula: Implications for sexual selection. Genetica 89:255-265.
Selivon D and Perondini ALP (1998) Eggshell morphology in two cryptic species of the Anastrepha fraterculus complex (Diptera, Tephritidae). Ann Entomol Soc Am 91:473-478.

Selivon D, Morgante JS and Perondini ALP (1999) Haldane's rule and other aspects of reproductive isolation observed in the Anastrepha fraterculus complex (Diptera, Tephritidae). Genet Mol Biol 22:507-510.

Selivon D, Perondini ALP and Morgante JS (2005) A geneticmorphological characterization of two cryptic species of Anastrepha fraterculus complex (Diptera, Tephritidae). Ann Entomol Soc Am 98:367-381

Selivon D, Vretos C, Fontes L and Perondini ALP (2004) New variant forms in the Anastrepha fraterculus complex (Diptera, Tephritidae). In: Barnes B (ed) Proc. 6th International Fruit Flies Symposium, Isteg Scientific Publ., South Africa, pp 253-258.

Smith-Caldas, MRB, McPheron BA, Silva JG and Zucchi RA (2001) Phylogenetic relationships among species of the fraterculus group (Anastrepha, Diptera, Tephritidae) inferred from DNA sequences of mitochondrial cytochrome oxidase I. Neotrop Entomol 30:565-573.

Tantawy AO and Mallah GS (1961) Studies on natural population of Drosophila. I. Heat resistance and geographical variation in Drosophila melanogaster and Drosophila simulans. Evolution 15:1-14.

Tornhill R (1992) Fluctuating asymmetry and the mating system of the Japanese scorpionfly, Planorpa japonica. Anim Behav 44:867-879.

Tsubaki Y (1998) Fluctuating asymmetry of the oriental fruit fly (Dacus dorsalis) during the process of its extinction from the Okinawa Island. Conservation Biol 12:926-929.

van Valen L (1962) A study of fluctuating asymmetry. Evolution 16:125-142.

Vera MT, Cáceres C, Wornoayporn V, Islam A, Robinson AS, De La Vega MH, Hendrichs J and Cayol J-P (2006) Mating incompatibility among populations of South American fruit fly Anastrepha fraterculus (Diptera, Tephritidae). Ann Entomol Soc Amer 99:387-397.

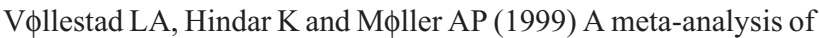
fluctuating asymmetry in relation to heterozygosity. Heredity 83:206-218.

White IM and Elson-Harris MM (1992) Fruit Flies of Economic Importance: Their Identification and Bionomics. CAB InterNational, Wallingford, pp 579.

Woods RE, Sgrò CM, Hercus MJ and Hoffmann AA (1999) The association between fluctuating asymmetry, trait variability, trait heritability, and stress: A multiply replicated experiment on combined stresses in Drosophila melanogaster. Evolution 53:493-505.

Zakharov VM (1992) Population phenogenetics: Analysis of developmental stability in natural populations. Acta Zool Fennic 19:7-30.

Zar JH (1999) Biostatistical Analysis. 4th edition. Prentice Hall Inc., New Jersey, pp 663.

Zucchi RA (2000) Espécies de Anastrepha, sinonímia, plantas hospedeiras e parasitóides. In: Malavasi A and Zucchi RA (eds) Moscas-das-Frutas de Importância Econômica no Brasil. Conhecimento Básico e Aplicado. Holos, Ribeirão Preto, pp 41-48.

Assistant Editor: Klaus Hartfelder 